\title{
Predator identity influences the effect of habitat management on nest predation
}

\author{
Timothy P. Lyons, ${ }^{1,5}$ James R. Miller,,${ }^{1,2}$ Diane M. Debinski,${ }^{3}$ and David M. Engle ${ }^{4}$ \\ ${ }^{1}$ Department of Natural Resources and Environmental Sciences, University of Illinois at Urbana-Champaign, \\ Urbana, Illinois 61801 USA \\ ${ }^{2}$ Graduate Program in Ecology, Evolution, and Conservation Biology, University of Illinois at Urbana-Champaign, \\ Urbana, Illinois 61801 USA \\ ${ }^{3}$ Department of Ecology Evolution, and Organismal Biology, Iowa State University, Ames, Iowa 50011 USA \\ ${ }^{4}$ Department of Natural Resource Ecology and Management, Oklahoma State University, Stillwater, Oklahoma 74078 USA
}

Abstract. Predation is the leading cause of nest failure for many passerines and considerable effort is devoted to identifying the habitat characteristics and management practices that influence nest loss. The habitat components associated with nest loss are strongly influenced by the ecology of nest predators and differ among predator species as a result. Nevertheless, there is a tendency to generalize about the effects of habitat features and management on nest failure without considering how resulting patterns are influenced by nest predators. We examined how predator-specific patterns of nest loss differed among predators and in response to grassland management with fire and grazing by cattle (Bos taurus). We used video cameras to monitor and identify predators at nests of the Grasshopper Sparrow (Ammodramus savannarum), a species of conservation concern throughout its range. We observed predation by 15 different species that differed in their response to management and the habitat characteristics associated with nests they preyed on. Losses to mammals and snakes were more likely at nests with greater amounts of litter cover and tall fescue (Schedonorus phoenix). Mammals were less likely to prey on nests surrounded by greater forb cover. Nest predation by snakes was lower in burned areas, whereas predation by mammals and Brown-headed Cowbirds (Molothrus ater) was unaffected by the use of fire. Neither vegetation density at the nest, nor landscape context was related to nest loss by any predator taxon. Although there were many similarities, we identified important differences in the species composing the nest predator community between our study and other published research. These differences are likely to be responsible for geographic variation in the influence of habitat features and management actions on nest success. Our results demonstrate the need for natural resource managers to incorporate knowledge of local nest predators and their ecology when developing management prescriptions aimed at enhancing the reproductive success of songbirds.

Key words: Ammodramus savannarum; cause-specific mortality; fire; Grasshopper Sparrow; grassland; grazing; habitat management; nest camera; nest loss; predator identification; Ringgold County, Iowa, USA.

\section{INTRODUCTION}

Nest predation is the leading cause of nest failure for many passerine species (Martin 1992, Thompson and Ribic 2012). Much research on this topic has focused on identifying ecological correlates that render a nest more or less likely to be preyed upon (Angelstam 1986, Vickery et al. 2001). In most cases, the focus has been on how predation patterns are related to habitat characteristics and landscape composition. Fragmented landscapes are commonly thought to be associated with high rates of nest loss (Robinson et al. 1995, Herkert et al.

Manuscript received 28 August 2014; revised 15 December 2014; accepted 7 January 2015. Corresponding Editor: D. Brunton.

${ }_{5}^{5}$ Present address: Illinois Natural History Survey, 1816 S. Oak Street, Champaign, Illinois 61820 USA.

E-mail: tlyons253@gmail.com
2003), particularly for nests close to habitat edges (Gates and Gysel 1978, Batáry and Báldi 2004). Such generalizations, however, are not universally upheld (Spanhove et al. 2009, Benson et al. 2013).

One reason that generalizations about the relationship between habitat characteristics and nest predation are often contradicted is that nest loss is more directly related to the identity, behavior, and activity patterns of nest predators (Lahti 2009, Benson et al. 2010). When only one or a few predator species are responsible for nest failure, a relatively strong relationship between environmental factors and patterns of nest loss can emerge (Grant et al. 2006, Sperry et al. 2008). Yet, in many systems, predator communities are diverse (Thompson and Burhans 2003, Ribic et al. 2012). In these systems, patterns of nest loss can be difficult to elucidate because the environmental features related to 
predator behavior differ among species or groups of predators (Benson et al. 2010).

Because observed patterns of nest loss are greatly affected by the predator community and autecology, it may be difficult to predict the outcome of management practices that alter habitat structure or composition without information about predator identity. Actions targeting specific predators can reduce losses by those species, but in diverse predator communities, such actions may result in compensatory mortality (EllisFelege et al. 2012, Ellison et al. 2013). Moreover, regional variation in nest predator communities may confound our ability to achieve a comprehensive assessment of the effects of habitat manipulations on patterns of nest failure (Pietz et al. 2012, DeGregorio et al. 2014). Characterizing the role of predator identity in the relationships among bird nest failure, habitat characteristics, and management is therefore important to improving conservation efforts.

In North America, many grasslands are managed with fire and/or grazing to achieve agronomic or conservation goals (Fuhlendorf et al. 2012), but the effects of fire and grazing on nest predation have been inconsistent (Johnson and Temple 1990, Shochat 2005, Churchwell et al. 2008, Rahmig et al. 2009, Kerns et al. 2010, Johnson et al. 2012). We suspect that these variable responses are due, at least in part, to interactions between habitat characteristics and different nest predator communities. Predator communities within grasslands are frequently diverse and include a variety of small- and medium-sized mammals, birds, and snakes (Pietz et al. 2012).

We documented nest predation patterns for the Grasshopper Sparrow (Ammodramus savannarum), a grassland obligate songbird in a landscape highly fragmented by tree cover and agriculture. The Grasshopper Sparrow is a species of conservation concern throughout much of its range (Panjabi et al. 2012). This species has experienced severe population declines (Sauer et al. 2003) and high rates of nest predation (Hovick et al. 2012). We examined the influence of fire and grazing, nest site characteristics, and landscape context on predation by mammals, snakes, and Brown-headed Cowbirds (Molothrus ater). Landscape context can influence the abundance and activity of mammals and Cowbirds and affect the risk of nest loss (Chalfoun et al. 2002). Conversely, fire reduces cover and insect abundance in pastures, which may reduce activity and predation by snakes and mammals in recently burned areas (Vickery et al. 1992, Cavitt 2000). Grazing is believed to adversely affect nest success by reducing vegetation density and concealment at nests. Thus, we expected effects of grazing to be manifested via increased predation at nests surrounded by sparse vegetation.

\section{Methods \\ Study area}

Our study was conducted on eight pastures in Ringgold County, Iowa, USA (Fig. 1), from 2010 to

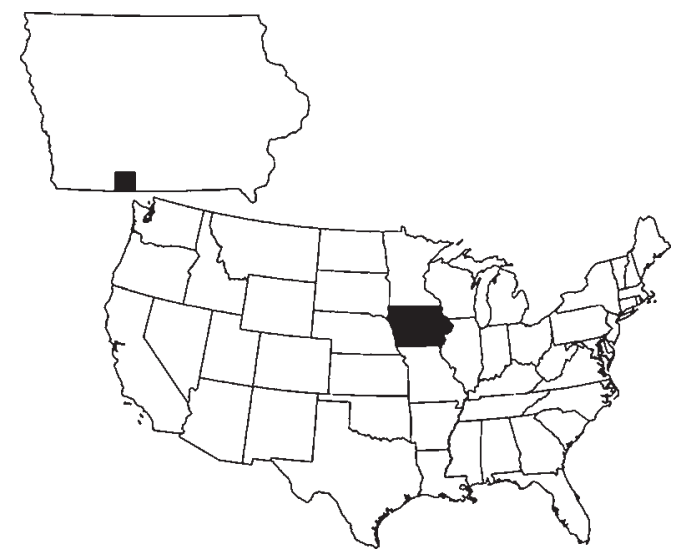

FIG. 1. Location of research pastures in Ringgold County, Iowa, USA.

2012. The landscapes surrounding these sites were highly fragmented and, on average, were composed of $58 \%$ grasslands and pastures, $18 \%$ row crops, $22 \%$ woodlands, and $2 \%$ residences and other impervious surfaces. (Lyons 2013). The study pastures were under the jurisdiction of the Iowa Department of Natural Resources, The Nature Conservancy, or were privately owned. Vegetation within pastures was dominated by graminoids, including both native and nonnative species. In most pastures, the dominant nonnative grass was tall fescue (Schedonorus phoenix), an invasive coolseason species (McGranahan et al. 2013a). Other herbaceous plants included forbs, sedges, native and exotic legumes, and scattered trees and shrubs (McGranahan et al. 2013a).

\section{Management treatment}

Research pastures ranged from 23-34 ha in area and were assigned to one of two treatments: patch-burn graze or graze-and-burn. One patch in each patch-burn graze pasture ( $n=4$ pastures) was burned every spring, so the entire pasture was burned once during the threeyear study. All patches within graze-and-burn pastures $(n=4)$ were burned in spring 2009 and again in 2012 to prevent the encroachment of woody vegetation. Pastures were stocked with cattle (Bos taurus) from May to September $(\bar{x}=1.98$ AUM [animal equivalent units per month] per ha, range: 1.09-3.85 AUM). Pastures were fenced along the perimeter and cattle had free access to the patches therein. Management with patch-burn grazing attempts to increase habitat heterogeneity within pastures via focal grazing in the most recently burned patch (Fuhlendorf et al. 2012).

\section{Nest monitoring}

We searched for nests from 05:30 to 12:00 hours (Central Standard Time) between 15 May and 29 July in each year of the study. Each pasture was searched three times in 2011 and four times in 2010 and 2012. Most nests were located by systematic rope-dragging (Higgins 
et al. 1969), using a 30-m rope with aluminum cans attached every $1.5 \mathrm{~m}$. Searchers placed flags at one end of the rope every $30-50 \mathrm{~m}$ to ensure complete coverage of pastures.

We recorded the location of nests with a GPS and placed flagging $5 \mathrm{~m}$ north and $5 \mathrm{~m}$ south to aid in relocation on subsequent visits. One host egg was candled to estimate nest age and to predict hatch date (Lokemoen and Koford 1996). If a nest contained nestlings, we aged the clutch based on feather growth characteristics, such as the emergence of pin feathers or primary feathers (Vickery 1996). We recorded clutch or brood size and the number of Brown-headed Cowbird eggs or nestlings at each visit (every 1-4 days), and documented loss of eggs or nestlings between visits.

\section{Video cameras}

Although sign at the nest has been used to determine predator-specific mortality, this method is notoriously inaccurate (Thompson and Burhans 2003). Instead, we used miniature video cameras to identify predators. We placed cameras at a subset of nests, distributing them such that approximately equal proportions of nests were monitored in each pasture and patch of each treatment. These cameras featured infrared $(950 \mathrm{~nm})$ light-emitting diodes (LEDs) that enabled us to continue recording at night (Cox et al. 2012a). We placed cameras at nests in late morning and early afternoon to minimize nest abandonment. Cameras remained in place until the nests produced fledglings or failed. We reviewed film to determine exact fledge dates and to identify predators if nest contents were removed between observer visits.

\section{Landscape and pasture measurements}

Activity and abundance of nest predators such as skunks (Mephitis mephitis), coyotes (Canis latrans), Brown-headed Cowbirds, and raccoons (Procyon lotor) may be influenced by tree cover or agricultural fields in the landscape, indirectly affecting patterns of nest mortality (Larivière and Messier 2000, Chalfoun et al. 2002, Kuehl and Clark 2002, Phillips et al. 2003). We therefore delineated woodland, grassland, open water, and agricultural fields within $1 \mathrm{~km}$ of each pasture. We selected a $1 \mathrm{~km}$ radius because variance in the proportions of land cover classes plateaued at this distance (Pillsbury et al. 2011). Further, nest predation may be strongly related to landscape characteristics at or near this distance (Bergin et al. 2000). Skunks, snakes, and Brown-headed Cowbirds tend to be more active near forest-field edges, streams, or ponds (Kuehl and Clark 2002, Weatherhead et al. 2010, Patten et al. 2011). We therefore calculated the distance from each nest to these features. Land cover was digitized in ArcGIS 10.0 (ESRI 2010) using 2011 true-color orthoimages with 2-m resolution (USDA 2011). Because activity and abundance of snakes and skunks are often lower in recently burned grasslands (Vickery et al. 1992, Cavitt
2000), we quantified time since fire $(0,1$, or 2 years) for each patch within a pasture.

\section{Nest site measurements}

We returned to each nest 3-7 days after its fate was determined to quantify vegetation composition and structure. These characteristics may reduce visual or olfactory cues, or diminish predator search efficiency (Bowman and Harris 1980, Benson et al. 2010). We placed one $0.5-\mathrm{m}^{2}$ quadrat at the nest cup and $5 \mathrm{~m}$ from the nest in each cardinal direction $(n=5$ quadrats per nest). Within each quadrat, we recorded percent cover of tall fescue, $\mathrm{C}_{4}$ grasses, forbs, bare ground, litter, and shrubs because these features are often related to nest failure of grassland birds or characterize the preferred habitat of some potential nest predators (Dion et al. 2000, Klug et al. 2010, Duggan et al. 2011). Cover was recorded as the midpoint of the following categories: 0 $5 \%, 6-25 \%, 26-50 \%, 51-75 \%, 76-95 \%$, and $96-100 \%$ (Daubenmire 1959). To quantify visual obstruction (a surrogate for vegetation height and density; Robel et al. 1970), we averaged four Robel pole readings made $4 \mathrm{~m}$ from each nest and measured at $1 \mathrm{~m}$ above ground in each cardinal direction.

\section{Analysis}

To ensure that the results of any predator-specific analyses were not systematically biased by the presence of cameras, we performed a preliminary analysis, comparing survival rates at nests with and without cameras using the logistic exposure method (Shaffer 2004). Because each interval between observer nest visits is an independent Bernoulli trial, cameras were included as an interval-specific covariate. If cameras did not record the female returning to her nest within four hours after we placed the camera, we attributed the abandonment to camera placement and censored these nests from further analyses. After censoring these nests, we found no difference in survival rates at nests with or without cameras (Lyons 2013).

We used multinomial logistic regression to compute daily predation probabilities for multiple classes of predator. In this analysis, our data set consisted of each 1-day interval when a nest was monitored with a camera. Similar to other nest survival analyses, each observation period is considered to be an independent trial and the fate of nests is assumed to be independent (Shaffer 2004). We separated day-fates into five categories: depredation by (1) Brown-headed Cowbirds, (2) snakes, and (3) mammals (raccoons, skunks, badgers, etc.); (4) loss due to other sources of failure (trampling, abandonment, predation by species other than the aforementioned, unknown predator due to camera failure, or natural causes); and (5) survived (were not depredated or did not fail due to previously mentioned causes). Our primary interest was in identifying factors related to nest loss by mammals, snakes, and Brownheaded Cowbirds, because these taxa are commonly 
implicated as nest predators and there is much interest in reducing their impact on threatened avian species (Hartway and Mills 2012, Thompson and Ribic 2012). To examine potential nonindependence of nest fates, we conducted a preliminary analysis whereby the patch and pasture in which a nest was located were considered random effects. Because estimates of these effects were zero, we considered the assumption of nest fate independence valid and did not include these variables in other models.

Because all nest contents are not always consumed in the same event (Pietz and Granfors 2000, Hovick et al. 2012), we included partial predation events. Ignoring these events would underestimate the impact of some predators. As a result, nests that experienced partial predation could be classified as "survived" following partial loss of eggs or young and our survival estimate equals the probability that a nest escaped the loss of any eggs or chicks. If cameras recorded multiple predation events by different species, we assumed that these events were independent and related to the environmental conditions associated with that nest. If the same predator species was recorded on camera removing eggs or nestlings on more than one occasion, we assumed that it was the same individual and that the events were related. If predation events were related, we censored the initial predation event from the data set and used only the event that resulted in complete nest failure.

To evaluate support for models explaining predatorspecific nest loss, we used an information-theoretic approach. Because sample sizes for each group were relatively small and additive models in multinomial regression are highly penalized (Cox et al. 2012b), we avoided complex models. We included only one or two variables in each model and restricted variable combinations by constructing models in a multistep process.

We developed a set of habitat- and managementrelated models in a three-stage process. First, we evaluated support for the effects of broadscale variables (tree cover, row-crop agriculture, and proximity to water and wooded edges) on patterns of nest loss. Next, we assessed the effect of treatment, pasture size, and time since fire. Finally, we examined the effect of habitat features within $5 \mathrm{~m}$ of the nest (cover of $\mathrm{C}_{4}$ grasses, litter, tall fescue, forbs, and visual obstruction). At each stage, we ranked models using Akaike's information criterion adjusted for small samples $\left(\mathrm{AIC}_{\mathrm{c}}\right)$. To generate multi-scale models, we added variables from one stage to the next only if they had a lower $\mathrm{AIC}_{\mathrm{c}}$ than a constant survival (null) model. This approach allowed us to quantify support for models with combinations of multiscale effects. Models from every stage in the modelbuilding process as well as multi-scale models were included in the candidate model set. Although all models were not identified a priori, this approach resulted in fewer overall models and reduced the risk of obtaining spurious results (Burnham and Anderson 2002, Dinsmore and Dinsmore 2007).
Predator abundance and activity may vary temporally and the visual and olfactory cues that predators use to locate nests vary during the nesting cycle. Therefore, we evaluated support for temporal variables using five models including a null. We considered the effects of year, nest stage, day of year, and the additive effects of day of year and nest stage. For all analyses, we examined correlations among all variables considered for inclusion to ensure that those that were highly correlated $(|r|>0.7)$ did not appear in the same model. Model fit was assessed using a likelihood ratio test between the global and null models. We also examined our results for evidence of overdispersion.

We ranked all models by $\mathrm{AIC}_{\mathrm{c}}$ score, and models within four $\mathrm{AIC}_{\mathrm{c}}$ units of the top model (lowest score) were considered to be competitive (Burnham and Anderson 2002). For the best and competitive models, we constructed $85 \%$ confidence intervals (CIs) of conditional parameter estimates to clarify the relationship among selected variables and nest loss attributed to different predator groups. We considered a parameter to be related to nest loss if the $85 \%$ CI did not overlap 0 . We used $85 \%$ confidence intervals because $\mathrm{AIC}_{\mathrm{c}}$ selection will support parameters at this level over a null model (Arnold 2010). We based our inference on conditional, rather than model-averaged, estimates because the inclusion of additional variables in multinomial regression is highly penalized (Cox et al. 2012b). As a result, models including parameters that are informative for only a single predator group may rank poorly despite the information that they contain. These informative, yet poorly ranked, models receive low weight when modelaveraging, reducing parameter estimates of ecologically meaningful variables to near zero.

\section{RESUlts}

We placed cameras at 135 Grasshopper Sparrow nests (36 in 2010, 48 in 2011, 51 in 2012). Twenty-one nests with cameras were abandoned and omitted from analysis. Only nests in the incubation stage were abandoned. Although we did not perform a formal statistical analysis, this rate was exceedingly greater than for nests not monitored with a camera ( $\mathrm{T}$. Lyons, personal observation). Our final data set for analysis included 807 observation days at 108 nests. We monitored nests with cameras for $7.5 \mathrm{~d}$, on average (range 1-20 d).

We identified individual predators responsible for 43 predation events. Mammals comprised the largest group of predators ( $n=21$ predation events; Appendix A) and included raccoons, badgers (Taxidea taxus), skunks, coyotes, and opossums (Didelphis virginiana). Snakes preyed on a smaller portion of nests $(n=12$ events; Appendix A). Brown-headed Cowbirds were responsible for few predation events ( $n=5$ events; Appendix A). We recorded single predation events by a white-tailed deer (Odocoileus virginianus), a Blue Jay (Cyanocitta cristata), a Red-tailed Hawk (Buteo jamaicensis), a Loggerhead 
TABLE 1. Model selection results of habitat and temporal factors related to predator-specific nest loss of Grasshopper Sparrows (Ammodramus savannarum).

\begin{tabular}{lcccc}
\hline \hline \multicolumn{1}{c}{ Model } & No. parameters & $\Delta \mathrm{AIC}_{\mathrm{c}}$ & Model weight & Deviance \\
\hline Habitat analysis & & & & \\
Step 1 & & & & \\
Null & 4 & 0.00 & 0.65 & 716.47 \\
Crop cover 1 km & 8 & 2.59 & 0.18 & 710.93 \\
Tree cover 1 km & 8 & 4.37 & 0.07 & 712.71 \\
Distance to water & 8 & 5.22 & 0.05 & 713.55 \\
Distance to wooded edge & 8 & 5.23 & 0.05 & 713.56 \\
Step 2 & & & & \\
Time since fire & 8 & 0.00 & 0.74 & 706.16 \\
Null & 4 & 2.18 & 0.25 & 716.47 \\
Treatment† & 8 & 8.48 & 0.01 & 714.64 \\
Pasture size & 8 & 9.55 & 0.01 & 715.70 \\
Step 3 & & & & \\
Time since fire + forb & 12 & 0.00 & 0.39 & 694.76 \\
Time since fire + litter & 12 & 0.32 & 0.33 & 695.08 \\
Time since fire + fescue & 12 & 2.85 & 0.09 & 697.61 \\
Time since fire & 8 & 3.18 & 0.08 & 706.16 \\
Time since fire + C 4 grass & 12 & 4.07 & 0.05 & 698.83 \\
Null & 4 & 5.36 & 0.03 & 716.47 \\
Time since fire + V.O. & 12 & 5.44 & 0.03 & 700.20 \\
Temporal analysis & & & & \\
Null & 4 & 0.00 & 0.61 & 716.47 \\
Stage & 8 & 1.98 & 0.23 & 710.31 \\
Ordinal day & 8 & 3.59 & 0.10 & 711.93 \\
Stage + ordinal day & 12 & 5.28 & 0.04 & 705.40 \\
Year & 12 & 7.10 & 0.02 & 707.23 \\
\hline
\end{tabular}

Notes: Step 1 included only broadscale habitat variables, step 2 included features at the pasture level, and step 3 included nest site variables. The variable V.O. is visual obstruction (a surrogate for vegetation height and density; Robel et al. 1970). Parameters ranked higher than the null were carried on to successive stages.

$\dagger$ Treatment refers to patch-burn grazed and grazed-and-burned pasture treatments.

$\$$ The highest ranked habitat model.

Shrike (Lanius ludovicianus), and a vole (Microtus spp.; Appendix A). We did not record any predation by thirteen-lined ground squirrels (Ictidomys tridecemlineatus), which are often the most common nest predator in other North American grasslands (Pietz et al. 2012). We observed removal of dead nestlings and an egg that failed to hatch by adult Grasshopper Sparrows at eight nests. These losses were attributed to inclement weather or unknown causes (Appendix A). Predation by mammals resulted in complete nest failure, whereas snakes were responsible for both partial and complete nest losses. Cowbird predation resulted only in partial losses. We recorded egg and chick removal by more than one species at three nests. We also observed a snake depredating the same nest on two separate occasions. Because this latter case could have been the same individual, making the two events nonindependent, it was only counted once.

Contrary to our predictions, we found no support for an effect of landscape characteristics on nest predation patterns. Instead, the best habitat model included support for pasture-level and nest site features. The best-supported model included an effect of time since fire within each patch and forb cover within $5 \mathrm{~m}$ of the nest, although there was nearly equivalent support for a model including litter rather than forb cover (Table 1).
Models including effects of time since fire and tall fescue cover were also competitive (Table 1).

Only predation by snakes was affected by time since fire (Table 2). Snake predation increased in the absence of fire and was 11 times more likely in patches that were last burned two years ago compared to recently burned patches (Table 2, Figs. 2 and 3). Snakes and mammals were more likely to prey on nests with more fescue and litter cover (Table 2, Figs. 2-4). Predation by mammals was less likely at nests with relatively greater amounts of forb cover (Table 2, Fig. 4). The best temporal model was the null, although effects of nest stage had some support (Table 1). Confidence intervals of conditional estimates of nest stage for snakes did not overlap zero (Table 2), indicating that snakes were more likely to prey on nests during the nestling stage. The overall estimated daily survival rate (conditional on the top-ranked model) was 0.906, whereas daily predation rates were 0.001 for Brown-headed Cowbirds, 0.010 for snakes, 0.023 for mammals, and 0.060 for other causes of mortality.

\section{Discussion}

Although habitat loss is undoubtedly the primary factor driving population declines of grassland songbirds, current rates of reproductive success may not be sufficient to sustain local or regional populations of 
TABLE 2. Conditional parameter estimates and $85 \%$ confidence limits (CL) from predator-specific analysis of nest predation of Grasshopper Sparrows.

\begin{tabular}{|c|c|c|c|c|}
\hline \multirow[b]{2}{*}{ Parameter } & \multirow[b]{2}{*}{ Coefficient, $\beta$} & \multirow[b]{2}{*}{$\mathrm{SE}$} & \multicolumn{2}{|c|}{$85 \% \mathrm{CL}$} \\
\hline & & & Lower & Upper \\
\hline \multicolumn{5}{|c|}{ Time since fire } \\
\hline Snake & 1.196 & 0.438 & 0.565 & 1.828 \\
\hline Cowbird & 0.613 & 0.539 & -0.163 & 1.390 \\
\hline Mammal & 0.151 & 0.267 & -0.234 & 0.535 \\
\hline \multicolumn{5}{|l|}{ Forb } \\
\hline Snake & -0.010 & 0.021 & -0.041 & 0.021 \\
\hline Cowbird & -0.047 & 0.035 & -0.098 & 0.004 \\
\hline Mammal & -0.046 & 0.017 & -0.071 & -0.021 \\
\hline \multicolumn{5}{|l|}{ Litter } \\
\hline Snake & 0.040 & 0.026 & 0.002 & 0.078 \\
\hline Cowbird & 0.071 & 0.050 & 0.000 & 0.143 \\
\hline Mammal & 0.032 & 0.016 & 0.009 & 0.055 \\
\hline \multicolumn{5}{|l|}{ Tall fescue } \\
\hline Snake & 0.035 & 0.016 & 0.013 & 0.058 \\
\hline Cowbirds & 0.024 & 0.023 & -0.009 & 0.05 \\
\hline Mammal & 0.019 & 0.011 & 0.003 & 0.036 \\
\hline \multicolumn{5}{|l|}{ Stage $\dagger$} \\
\hline Snake & -1.290 & 0.778 & -2.411 & -0.168 \\
\hline Cowbird & -1.066 & 1.121 & -2.681 & 0.548 \\
\hline Mammal & -0.596 & 0.489 & -1.301 & 0.108 \\
\hline
\end{tabular}

Notes: Parameter estimates are conditional on the highest ranked model including that variable, provided that the model was $\leq 4 \Delta \mathrm{AIC}_{\mathrm{c}}$ from the best model. Coefficients and $85 \%$ confidence intervals in bold are considered informative because they do not overlap zero.

$\uparrow$ The effect is expressed as the predation risk during incubation compared to the nestling stage.

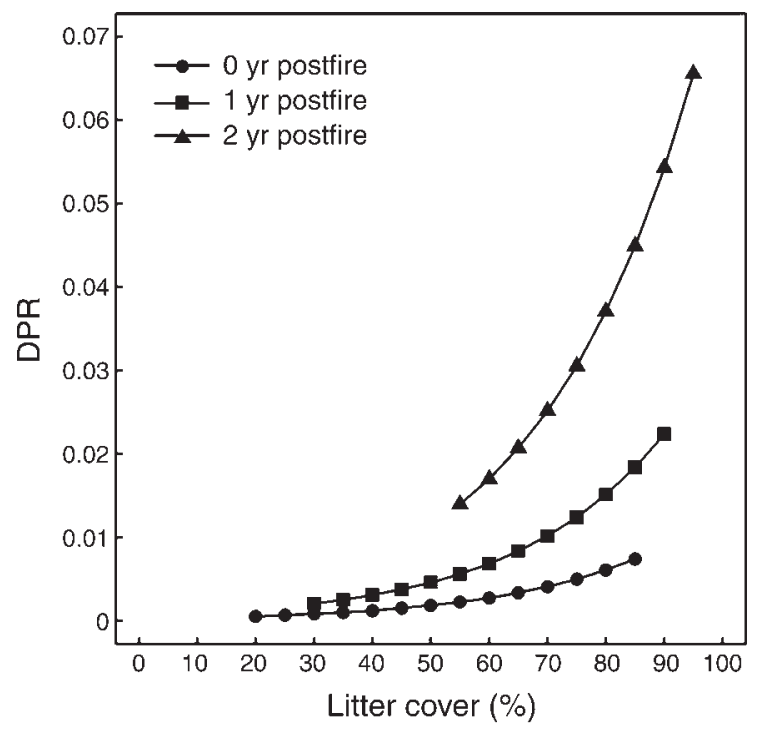

FIG. 2. Daily predation rate (DPR) of Grasshopper Sparrow (Ammodramus savannarum) nests for snakes as a function of time since fire and litter cover. DPR is the estimated probability that a nest will be preyed upon, on any given day. Nest predation increases in the absence of fire and as litter cover at the nest increases.

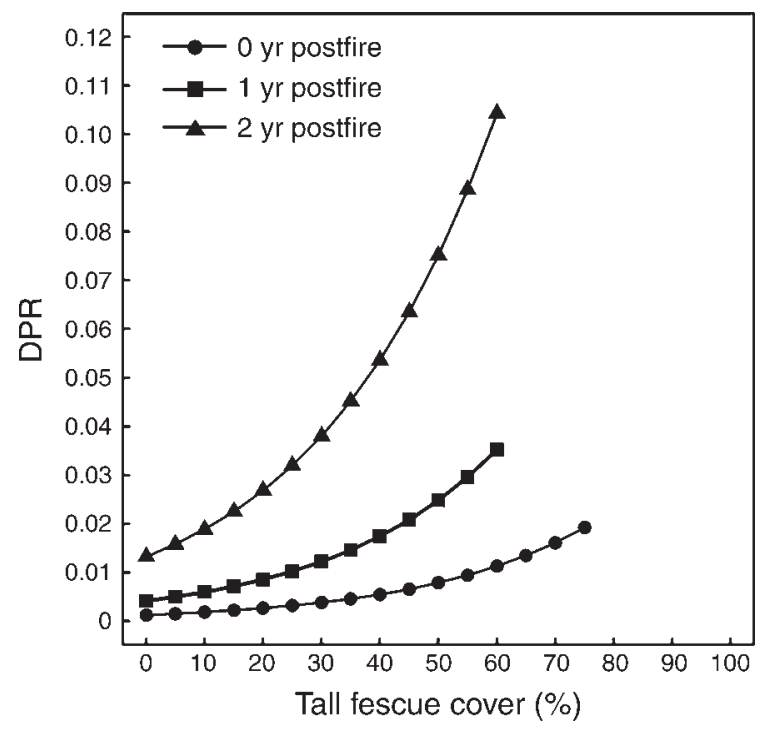

FIG. 3. Daily predation rate (DPR) of Grasshopper Sparrow nests for snakes as a function of time since fire and tall fescue cover. Nest predation increases in the absence of fire and as tall fescue cover at the nest increases.

many species long term, including Grasshopper Sparrows (With et al. 2008, Hovick and Miller 2013). Therefore, evaluating habitat management techniques that reduce nest loss is crucial. A recent meta-analysis concludes that fire reduces nest predation in North American grasslands (Hartway and Mills 2012), yet in some locations, fire is associated with increased nest loss for grassland birds (Churchwell et al. 2008, Rahmig et al. 2009). We found that fire only reduced predation by snakes, which underscores the importance of considering how habitat manipulations affect particular classes of predators. In tallgrass prairie, fire reduces both the relative abundance and activity of grassland snakes (Cavitt 2000). The effectiveness of fire in reducing nest loss by snakes may be attributed to their avoidance of recently burned areas, where they are more visible to their own predators (Setser and Cavitt 2003, Wilgers and Horne 2007), at least until plant growth reaches a sufficient stage of recovery.

The importance of vegetative cover for snakes may also explain our finding that nest predation increased with greater amounts of tall fescue and litter cover. Increased cover of $\mathrm{C}_{3}$ grasses such as fescue has been related to higher nest predation elsewhere, although the underlying cause is not well understood (Giuliano and Daves 2002). It is unlikely that snakes preferentially use fescue per se, but they may benefit indirectly from its presence. Fescue becomes photosynthetically active at our sites when most $\mathrm{C}_{4}$ grasses are still dormant. It reduces fire spread (McGranahan et al. 2013c) and results in greater amounts of litter and and more dense vegetation that could serve as snake habitat, especially following spring fires. 


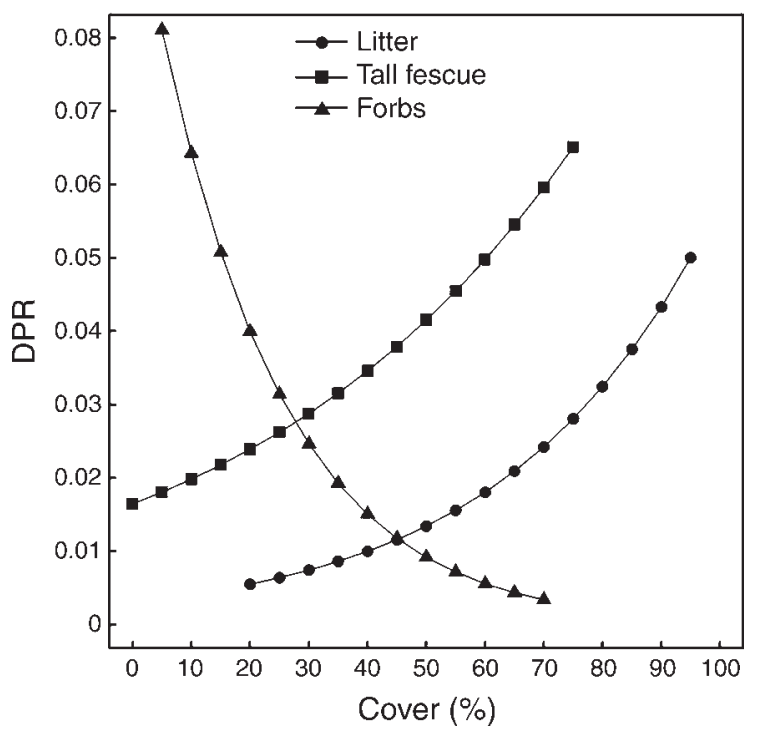

FIG. 4. Daily predation rate (DPR) of Grasshopper Sparrow nests for mammals as a function of vegetative cover at the nest (based on conditional model estimates). The odds that a nest will be preyed on by a mammal decreases with increasing forb cover, but increases with increasing cover of litter and tall fescue.

Nests with relatively more tall fescue and litter cover were also more likely to be preyed on by mammals. The synergistic effect of fescue and litter may create preferred foraging habitat for mammalian nest predators, again indirectly increasing the risk of nest loss (Vickery et al. 1992, Klug et al. 2009). However, the odds of mammalian predation decreased with increasing forb cover at nests. Increased forb cover has been related to improved nest and fledgling success and lower levels of mammal activity (Dion et al. 2000, Berkeley et al. 2007). Although the cause of this relationship is unclear, forb cover can contribute to the structural diversity and complexity of grasslands, which may also increase predator search time, resulting in lower rates of nest loss (Bowman and Harris 1980). Nevertheless, others report an increased risk of predation for Grasshopper Sparrows with increasing forb cover (Ribic et al. 2012).

The stocking rate of cattle in pastures affects the amount of residual vegetation at songbird nests (Johnson et al. 2012). Thus, reducing or eliminating grazing pressure increases vegetation density at nests and is hypothesized to reduce nest loss. In our study, grazing pressure varied within and among pastures (Scasta 2014) and resulted in a range of visual obstruction measurements at nests $(1.14-6.25 \mathrm{dm})$. Still, we did not detect any effect of grazing on nest predation, insofar as it related to vegetation structure surrounding nests. Whether or not grazing affects nest predation is likely to depend on whether predators are relying on visual cues to locate nests. Others have reported that vegetation density at the nest only influences predation by diurnal predators (Pietz and Granfors 2000). In our study, predation events by mammals occurred almost exclusively at night. We documented predation by snakes and Brown-headed Cowbirds during the day and at night, but the snakes in our study rely primarily on olfactory cues to locate prey (Chiszar et al. 1981) and Cowbirds do not necessarily depredate nests upon discovery (Arcese et al. 1996). Changes in vegetation density due to grazing can influence the predator community within pastures, although such changes may not ultimately affect nest predation rates (Ribic et al. 2012).

Cowbirds, mammals, and snakes are more likely to prey on bird nests near wooded edges in some systems (Benson et al. 2010, Cox et al. 2012b, Ellison et al. 2013), but we found no evidence of this pattern for any predator group. Still, the pervasiveness of wooded edges in our landscape may limit detection of edge effects (Hovick et al. 2012). Although edges may facilitate thermoregulation for snakes and serve as perches for Brown-headed Cowbirds (Weatherhead et al. 2010, Patten et al. 2011) increasing predator activity or abundance near edges, wooded edges may not fulfill the same role for predators in our system. Snakes may use shrubs within pastures for thermoregulation (Klug et al. 2010) and Cowbirds may use other perch sites such as fence lines. Collectively, these alternatives may dilute the influence of wooded edges in our study area. Similarly, landscape composition has been reported to influence nest success elsewhere (Winter et al. 2006), but we did not find that land cover within $1 \mathrm{~km}$ of pastures had an effect on predation patterns. Variability in land cover around our study pastures may have been insufficient to discern relationships with the species that we observed depredating nests (Appendix B), or predators could exhibit a threshold response to landscape composition, similar to that of some grassland songbirds (Thompson et al. 2014).

Reducing woody vegetation in the landscape is often seen as a desirable goal in grasslands bird conservation, but in our study region, manipulating habitat characteristics within pastures may be a more effective means of increasing nest success. Fire and grazing may be helpful tools, due to their effects on predators or their ability to create the habitat conditions that we related to a reduced risk of predation. Fire reduced nest lost because of predator-specific responses to disturbance, whereas grazing, in our study, had no apparent effect on nest predation. Disking or the application of fire and grazing have been shown to increase forb cover and reduce litter cover (Benson et al. 2007, McGranahan et al. 2013b). Fescue can be controlled with herbicide, prescribed fire, or grazing (Johnson and Sandercock 2010, Hall et al. 2012), and may benefit a variety of other grassland-dependent wildlife species as well (Madison et al. 2001, Moranz et al. 2012).

Predation patterns are a function of the composition of the nest predator community in a given location and the autecology of these species (Benson et al. 2010). The 
effect of management actions on patterns of nest loss will therefore depend on how different predators respond to particular disturbances, how changes in habitat characteristics affect the availability of food or cover that they prefer, and how habitat features interact with the sensory modalities that different species use to locate nests. As a result, variation in predator community composition probably accounts for the differences in the relationship between habitat features and nest loss that we observed, compared to results from studies in other regions. More broadly, this explains why generalizations about the effects of ecological processes, landscape features, and local habitat characteristics on patterns of nest loss are not well supported (Thompson and Ribic 2012). Different responses among predators complicate management aimed at reducing nest loss, because actions aimed at reducing losses by one species may have no effect or may even indirectly benefit other predator taxa (Ellis-Felege et al. 2012, Ellison et al. 2013). The expanding use of miniature video cameras to identify nest predators (Cox et al. 2012a) can provide a more accurate picture of local predator communities and their responses to habitat management. Clarifying how habitat management affects both individual predators and predator communities will help managers to identify a suite of actions best suited to local conditions.

\section{AcKNowledgments}

Funding for this research was provided by the Iowa State Wildlife Grants Program (grant U-2-R-1) in cooperation with the U.S. Fish and Wildlife Service, Wildlife and Sport Fish Restoration Program; the Oklahoma Agricultural Experiment Station; Iowa State University; and the University of Illinois. Additional support was provided by the Wildlife Diversity Small Grant Program of the Iowa DNR, the Iowa Ornithologists' Union, the Illinois Federation for Outdoor Resources, and the Jonathan Baldwin Turner Graduate Fellowship from the University of Illinois College of Agriculture, Consumer, and Environmental Sciences. We are grateful for the field assistance of C. Duchardt, J. Pitzenberger, C. Priest, A. Keigher, and C. Krassa. We also thank R. Harr, S. Rusk, and T. Hovick for their assistance in data collection and logistical support. We especially thank $T$. Benson for his guidance in the use of cameras and analysis. The manuscript was improved by the thoughtful comments of two anonymous reviewers.

\section{Literature Cited}

Angelstam, P. 1986. Predation on ground-nesting birds' nests in relation to predator densities and habitat edge. Oikos 47:365373.

Arcese, P., J. N. M. Smith, and M. I. Hatch. 1996. Nest predation by cowbirds and its consequences for passerine demography. Proceedings of the National Academy of Sciences USA 93:4608-4611.

Arnold, T. W. 2010. Uninformative parameters and model selection using Akaike's Information Criterion. Journal of Wildlife Management 74:1175-1178.

Batáry, P., and A. Báldi. 2004. Evidence of an edge effect on avian nest success. Conservation Biology 18:389-400.

Benson, T. J., J. D. Brown, and J. C. Bednarz. 2010. Identifying predators clarifies predictors of nest success in a temperate passerine. Journal of Animal Ecology 79:225-234.

Benson, T. J., S. J. Chiavacci, and M. P. Ward. 2013. Patch size and edge proximity are useful predictors of brood parasitism, but not nest survival of grassland birds. Ecological Applications 23:879-887.

Benson, T. J., J. J. Dinsmore, and W. L. Hohman. 2007. Responses of plants and arthropods to burning and disking of riparian habitats. Journal of Wildlife Management 71:1949-1957.

Bergin, T. M., L. B. Best, K. E. Freemark, and K. J. Koehler. 2000. Effects of landscape structure on nest predation in roadsides of a Midwestern agroecosystem: a multiscale analysis. Landscape Ecology 2:131-143.

Berkeley, L. I., J. P. McCarty, and L. L. Wolfenbarger. 2007. Postfledging survival and movement of Dickcissels (Spiza americana), implications for habitat management and conservation. Auk 124:396-409.

Bowman, G. B., and L. D. Harris. 1980. Effects of spatial heterogeneity on ground-nest depredation. Journal of Wildlife Management 44:806-813.

Burnham, K. P., and D. R. Anderson. 2002. Model selection and multimodel inference, a practical information-theoretic approach. Second edition. Springer-Verlag, New York, New York, USA.

Cavitt, J. F. 2000. Fire and a tallgrass prairie reptile community: effects on relative abundance and seasonal activity. Journal of Herpetology 34:12-20.

Chalfoun, A. D., F. R. Thompson III, and M. J. Ratnaswamy. 2002. Nest predators and fragmentation: a review and metaanalysis. Conservation Biology 16:306-318.

Chiszar, D., S. V. Taylor, C. W. Radcliffe, H. M. Smith, and B. O'Connell. 1981. Effects of chemical and visual stimuli upon chemosensory searching by garter snakes and rattlesnakes. Journal of Herpetology 15:415-424.

Churchwell, R. T., C. A. Davis, S. D. Fuhlendorf, and D. M. Engle. 2008. Effects of patch-burn management on dickcissel nest success in a tallgrass prairie. Journal of Wildlife Management 72:1596-1604.

Cox, W. A., M. S. Pruett, T. J. Benson, S. J. Chiavacci, and F. R. Thompson III. 2012a. Development of camera technology for monitoring nests. Studies in Avian Biology 43:185-201.

Cox, W. A., F. R. Thompson III, and J. Faaborg. $2012 b$. Landscape forest cover and edge effects on songbird nest predation vary by predator. Landscape Ecology 27:659-669. Daubenmire, R. 1959. A canopy-coverage method of vegetational analysis. Northwest Science 33:43-64.

DeGregorio, B. A., S. J. Chiavacci, P. J. Weatherhead, J. D. Willson, T. J. Benson, and J. H. Speery. 2014. Snake predation on North American nests: culprits, patterns, and future directions. Journal of Avian Biology 45:325-333.

Dinsmore, S. J., and J. J. Dinsmore, 2007. Modeling avian nest survival in program MARK. Studies in Avian Biology 34:7383.

Dion, N., K. A. Hobson, and S. Larivière. 2000. Interactive effects of vegetation and predators on the success of natural and simulated nests of grassland songbirds. Condor 102:629634.

Duggan, J. M., R. L. Schooley, and E. J. Heske. 2011. Modeling occupancy dynamics of a rare species, Franklin's ground squirrel, with limited data: are simple connectivity metrics adequate? Landscape Ecology 26:1477-1490.

Ellis-Felege, S. N., M. J. Conroy, W. E. Palmer, and J. P. Carroll. 2012. Predator reduction results in compensatory shifts in losses of avian ground nests. Journal of Applied Ecology 49:661-669.

Ellison, K. S., C. A. Ribic, D. W. Sample, M. J. Fawcett, and J. D. Dadisman. 2013. Impacts of tree rows on grassland birds and potential nest predators: a removal experiment. PLoS ONE 8:e59151.

ESRI. 2010. ArcGIS 10.0. Environmental Systems Research Institute, Redlands, California, USA.

Fuhlendorf, S. D., D. M. Engle, R. D. Elmore, R. F. Limb, and T. G. Bidwell. 2012. Conservation of pattern and process: 
developing an alternative paradigm of rangeland management. Rangeland Ecology and Management 65:579-589.

Gates, J. E., and L. W. Gysel. 1978. Avian nest dispersion and fledging success in field-forest ecotones. Ecology 59:871-883.

Giuliano, W. M., and S. E. Daves. 2002. Avian response to warm-season grass use in pasture and hayfield management. Biological Conservation 106:1-9.

Grant, T. A., E. M. Madden, T. L. Shaffer, P. J. Pietz, G. B. Berkey, and N. J. Kadrmas. 2006. Nest survival of claycolored and vesper sparrows in relation to woodland edge in mixed-grass prairies. Journal of Wildlife Management 70:691-701.

Hall, S. L., R. L. McCulley, and R. J. Barney. 2012. Restoration of native warm season grassland species in a tall fescue pasture using prescribed fire and herbicides. Restoration Ecology 20:194-201.

Hartway, C., and L. S. Mills. 2012. A meta-analysis of the effects of common management actions on the nest success of North American birds. Conservation Biology 26:657-666.

Herkert, J. R., et al. 2003. Effects of prairie fragmentation on the nest success of breeding birds in the midcontinental United States. Conservation Biology 17:587-594.

Higgins, K. F., L. M. Kirsch, and I. J. Ball. 1969. A cable-chain device for locating duck nests. Journal of Wildlife Management 33:235-242.

Hovick, T. J., and J. R. Miller. 2013. Heterogeneity at multiple scales influences parasitism rates of a grassland bird. Landscape Ecology 28:1493-1503.

Hovick, T. J., J. R. Miller, S. J. Dinsmore, D. M. Engle, D. M. Debinski, and S. D. Fuhlendorf. 2012. Effects of fire and grazing on grasshopper sparrow nest survival. Journal of Wildlife Management 76:19-27.

Johnson, R. G., and S. A. Temple. 1990. Nest predation and brood parasitism of tallgrass prairie birds. Journal of Wildlife Management 54:106-111.

Johnson, T. N., P. L. Kennedy, and M. A. Etterson. 2012. Nest success and cause-specific nest failure of grassland passerines breeding in prairie grazed by livestock. Journal of Wildlife Management 76:1607-1616.

Johnson, T. N., and B. K. Sandercock. 2010. Restoring tallgrass prairie and grassland bird populations in tall fescue pastures with winter grazing. Rangeland Ecology and Management 63:679-688.

Kerns, C. K., M. R. Ryan, R. K. Murphy, F. R. Thompson III, and C. S. Rubin. 2010. Factors affecting songbird nest survival in northern mixed-grass prairie. Journal of Wildlife Management 74:257-264.

Klug, P. E., S. L. Jackrel, and K. A. With. 2010. Linking snake habitat use to nest predation risk in grassland birds: the dangers of shrub cover. Oecologia 162:803-813.

Klug, P. E., L. Wolfenbarger, and J. P. McCarty. 2009. The nest predator community of grassland birds responds to agroecosystem habitat at multiple scales. Ecography 32:973982.

Kuehl, A. K., and W. R. Clark. 2002. Predator activity related to landscape features in northern Iowa. Journal of Wildlife Management 66:1224-1234.

Lahti, D. C. 2009. Why we have been unable to generalize about bird nest predation. Animal Conservation 12:279-281.

Larivière, S., and F. Messier. 2000. Habitat selection and use of edges by striped skunks in the Canadian prairies. Canadian Journal of Zoology 78:366-372.

Lokemoen, J. T., and R. R. Koford. 1996. Using candlers to determine the incubation stage of passerine eggs. Journal of Field Ornithology 67:660-668.

Lyons, T. P. 2013. Nest predation and habitat selection in the grasshopper sparrow (Ammodramus savannarum). Thesis. University of Illinois, Urbana, Illinois, USA.

Madison, L. A., T. G. Barnes, and J. D. Sole. 2001. Effectiveness of fire, disking, and herbicide to renovate tall fescue fields to northern bobwhite habitat. Wildlife Society Bulletin 29:706-712.

Martin, T. E. 1992. Breeding productivity consideration-what are the appropriate habitat features for management? Pages 455-473 in J. M. Hagan III and D. W. Johnston, editors. Ecology and conservation of neotropical migrant landbirds. Smithsonian Institution Press, Washington, D.C., USA.

McGranahan, D. A., D. M. Engle, S. Fuhlendorf, J. R. Miller, and D. M. Debinski. 2013a. Multivariate analysis of rangeland vegetation and soil organic carbon describes degredation, informs restoration and conservation. Land $2: 328-350$.

McGranahan, D. A., D. M. Engle, S. D. Fuhlendorf, S. L. Winter, J. R. Miller, and D. M. Debinski. 2013b. Inconsistent outcomes of heterogeneity-based management underscore importance of matching evaluation to conservation objectives. Environmental Science and Policy 31:53-60.

McGranahan, D. A., D. M. Engle, J. R. Miller, and D. M. Debinski. 2013c. An invasive grass increases live fuel proportion and reduces fire spread in a simulated grassland. Ecosystems 16:158-169.

Moranz, R. A., D. M. Debinski, D. A. McGranahan, D. M. Engle, and J. R. Miller. 2012. Untangling the effects of fire, grazing, and land-use legacies on grassland butterfly communities. Biodiversity Conservation 21:2719-2746.

Panjabi, A. O., P. J. Blancher, R. Dettmers, and K. V. Rosenberg. 2012. Partners in Flight Handbook on Species Assessment. Partners in Flight Technical Series No. 3. http:// rmbo.org/pubs/downloads/PIFHandbook2012.pdf

Patten, M. A., D. L. Reinking, and D. H. Wolfe. 2011. Hierarchical cues in brood parasite nest selection. Journal of Ornithology 152:521-532.

Phillips, M. L., W. R. Clark, M. A. Sovada, D. J. Horn, R. R. Koford, and R. J. Greenwood. 2003. Predator selection of prairie landscape features and its relation to duck nest success. Journal of Wildlife Management 67:104-114.

Pietz, P. J., and D. A. Granfors. 2000. Identifying predators and fates of grassland passerine nests using miniature video cameras. Journal of Wildlife Management 64:71-87.

Pietz, P. J., D. A. Granfors, and C. A. Ribic. 2012. Knowledge gained from video-monitoring grassland passerine nests. Studies in Avian Biology 43:3-22.

Pillsbury, F. C., J. R. Miller, D. M. Debinski, and D. M. Engle. 2011. Another tool in the toolbox? Using fire and grazing to promote bird diversity in highly fragmented landscapes. Ecosphere 2(3): $\operatorname{art} 28$.

Rahmig, C. J., W. E. Jensen, and K. A. With. 2009. Grassland bird responses to land management in the largest remaining tallgrass prairie. Conservation Biology 23:420-432.

Ribic, C. A., M. J. Guzy, T. J. Anderson, D. W. Sample, and J. Nack. 2012. Bird productivity and nest predation in agricultural grasslands. Studies in Avian Biology 43:119-134.

Robel, R. J., J. N. Briggs, A. D. Dayton, and L. C. Hulbert. 1970. Relationships between visual obstruction measurements and weight of grassland vegetation. Journal of Range Management 23:295-297.

Robinson, S. K., F. R. Thompson III, T. M. Donovan, D. R. Whitehead, and J. Faaborg. 1995. Regional forest fragmentation and the nesting success of migratory birds. Science 267:1987-1990.

Sauer, J. R., J. E. Fallon, and R. Johnson. 2003. Use of North American Breeding Bird Survey data to estimate population change for bird conservation regions. Journal of Wildlife Management 67:372-389.

Scasta, J. D. 2014. Implications of pyric-herbivory on Central North American grassland ecology, management and production. Dissertation. Oklahoma State University, Stillwater, Oklahoma, USA.

Setser, K., and J. F. Cavitt. 2003. Effects of burning on snakes in Kansas, USA, tallgrass prairie. Natural Areas Journal 23:315-319. 
Shaffer, T. L. 2004. A unified approach to analyzing nest success. Auk 121:526-540.

Shochat, E. 2005. Ecological traps in isodars: effects of tallgrass prairie management on bird nest success. Oikos 111:159-169.

Spanhove, T., V. Lehouck, P. Boets, and L. Lens. 2009. Forest fragmentation relaxes natural nest predation in an Afromontane forest. Animal Conservation 12:267-275.

Sperry, J. H., R. G. Peak, D. A. Cimprich, and P. J. Weatherhead. 2008. Snake activity affects seasonal variation in nest predation risk for birds. Journal of Avian Biology 39:379-383.

Thompson, F. R., III, and D. E. Burhans. 2003. Predation of songbird nests differs by predator and between field and forest habitats. Journal of Wildlife Management 67:408-416.

Thompson, F. R., III, and C. A. Ribic. 2012. Conservation implications when the nest predators are known. Studies in Avian Biology 43:23-34.

Thompson, S. J., T. W. Arnold, and C. L. Amundson. 2014. A multiscale assessment of tree avoidance by prairie birds. Condor 116:303-315.

USDA (U.S. Department of Agriculture). 2011. USDA National Agriculture Imagery Program. Iowa Geographic Map Server. http://ortho.gis.iastate.edu

Vickery, J. A., J. R. Tallowin, R. E. Feber, E. J. Asteraki, P. W. Atkinson, R. J. Fuller, and V. K. Brown. 2001. The management of lowland neutral grasslands in Britain: effects of agricultural practices on birds and their food resources. Journal of Applied Ecology 38:647-664.

Vickery, P. D. 1996. Grasshopper Sparrow (Ammodramus savannarum). Number 239 in A. Poole, editor. The birds of North America online. http://bna.birds.cornell.edu/bna/ species/239

Vickery, P. D., M. L. Hunter, and J. V. Wells. 1992. Evidence of incidental nest predation and its effects on nests of threatened grassland birds. Oikos 63:281-288.

Weatherhead, P. J., G. L. F. Carfagno, J. H. Sperry, J. D. Brawn, and S. K. Robinson. 2010. Linking snake behavior to nest predation in a midwestern bird community. Ecological Applications 20:234-241.

Wilgers, D. J., and E. A. Horne. 2007. Spatial variation in predation attempts on artificial snakes in a fire-disturbed tallgrass prairie. Southwestern Naturalist 52:263-270.

Winter, M., D. H. Johnson, J. A. Shaffer, T. M. Donovan, and W. D. Svedarsky. 2006. Patch size and landscape effects on density and nesting success of grassland birds. Journal of Wildlife Management 70:158-172.

With, K. A., A. W. King, and W. E. Jensen. 2008. Remaining large grasslands may not be sufficient to prevent grassland bird declines. Biological Conservation 141:3152-3167.

\section{Supplemental Material}

Ecological Archives

Appendices A and B are available online: http://dx.doi.org/10.1890/14-1641.1.sm

Data Availability

Data used for analysis have been deposited at http://dx.doi.org/10.6084/m9.figshare.1291209 